\title{
Bis(oxazoline)-copper complexes, immobilized by electrostatic interactions, as catalysts for enantioselective aziridination
}

\author{
José M. Fraile, José I. García, Gustavo Lafuente, José A. Mayoral,* and Luis Salvatella \\ Departamento de Química Orgánica. Instituto de Ciencia de Materiales de Aragón. Facultad de \\ Ciencias. Universidad de Zaragoza-C.S.I.C. E-50009 Zaragoza (Spain) \\ E-mail: mayoral@unizar.es
}

\author{
Dedicated to Prof. Enrique Meléndez on his $70^{\text {th }}$ birthday
}

(received 06 Oct 03; accepted 16 Dec 03; published on the web 27 Dec 03)

\begin{abstract}
Immobilization of chiral bis(oxazoline)-copper complexes by electrostatic interactions with anionic supports leads to recyclable catalysts for aziridination between styrene and $(p$ toluensulfonylimino)phenyliodinane as a nitrene precursor. Although the yields are good in all the cases, enantioselectivity depends on the nature of the chiral ligand. With a bis(oxazoline) bearing phenyl substituents, the enantioselectivity is always around $25 \%$ ee, as in solution. When the chiral ligand has tert-butyl groups, enantioselectivity is noticeably lower than that observed in homogeneous phase as a consequence of the presence of free copper on the solid.
\end{abstract}

Keywords: Aziridines, immobilization, asymmetric catalysis

\section{Introduction}

The importance of aziridines comes not only from their presence in many natural products but also from their use as building blocks in the synthesis of nitrogen-containing compounds, and as chiral auxiliaries or ligands in asymmetric synthesis. ${ }^{1,2}$ In spite of this importance, the studies on the enantioselective preparation of aziridines are rather scarce, particularly when compared with the development of epoxidation chiral catalysts. ${ }^{3}$

Bis(oxazoline)-copper complexes were tested by Evans and coworkers as chiral catalysts in the aziridination of alkenes with nitrene precursors, ${ }^{4}$ and modifications on the tether between the oxazoline rings were later described. ${ }^{5}$ It has been more recently reported that the results with the same type of catalyst can be improved by using a better nitrene precursor. ${ }^{6}$

Our group has shown that bis(oxazoline)-copper complexes, immobilized by electrostatic interactions on anionic supports, are efficient and recoverable catalysts for enantioselective cyclopropanation reactions. $^{7-9}$ In this paper we explore the use of these solids to promote 
enantioselective aziridination between styrene and ( $p$-toluensulfonylimino)phenyliodinane (Scheme 1).
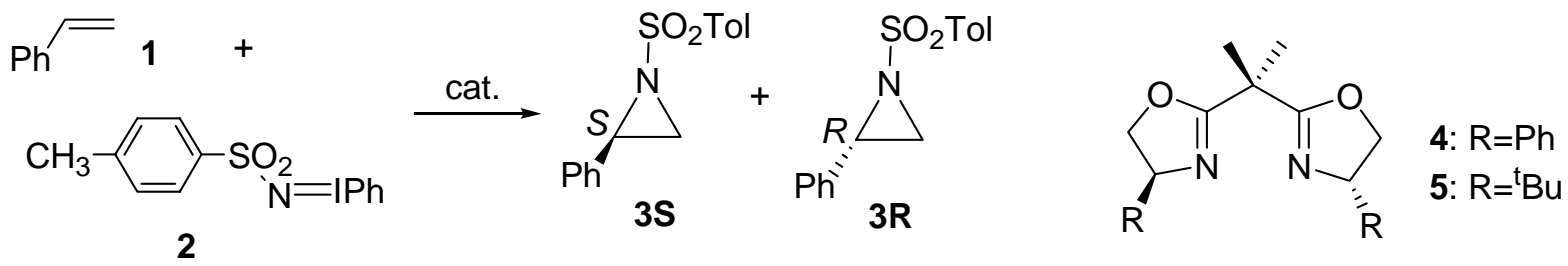

Scheme 1. Aziridination reaction between styrene (1) and ( $p$-toluensulfonylimino) phenyliodinane (2).

\section{Results and Discussion}

Based on previous cyclopropanation results, bis(oxazoline)-copper(II) complexes were immobilized on three different anionic supports: laponite, a synthetic clay; SAC-13, a nafionsilica nanocomposite with $13 \%$ nafion content; ${ }^{10}$ and $\mathrm{SiO}_{2}-\mathrm{CF}_{2} \mathrm{SO}_{3} \mathrm{H}$, prepared by grafting a partially fluorinated chain with a sulfonic acid group $\left[\equiv \mathrm{Si}-\left(\mathrm{CH}_{2}\right)_{3}-\left(\mathrm{CF}_{2}\right)_{2}-\mathrm{O}-\left(\mathrm{CF}_{2}\right)_{2} \mathrm{SO}_{3} \mathrm{H}\right]$ on silica gel. ${ }^{11}$ Immobilization was carried out by cationic exchange of bis(oxazoline)-Cu(OTf $)_{2}$ in methanol using the sodium form of the supports. Elemental analysis (Table 1) shows that the loading of complex depends on the structure of the chiral bis(oxazoline) ligand and the nature of the solid support. On laponite the copper content is lower in the case of ligand 5 because the complex is exchanged only on the external part of the solid, whereas part of the 4-Cu(II) complex is intercalated between the clay sheets. ${ }^{8}$ The loading on SAC-13 is very low, in agreement with the low functionalization of the solid (only $13 \%$ nafion). In the case of $\mathrm{SiO}_{2}$ $\mathrm{CF}_{2} \mathrm{SO}_{3} \mathrm{H}$, the loading of 4-Cu(II) exceeds the theoretical amount with total exchange $(0.25$ $\mathrm{mmol} / \mathrm{g}$ from $0.5 \mathrm{meq} / \mathrm{g}$ ). Sulfur analysis of the residue after exchange shows that part of the triflate remains on the solid, probably due to substitution of only one of the triflate counter-ions of $4-\mathrm{Cu}(\mathrm{OTf})_{2}$ with the anionic centers of the solid. ${ }^{9}$

Table 1. Characterization of the heterogeneous catalysts

\begin{tabular}{llll}
\hline Support & Ligand & $\mathrm{Cu}$ content $(\mathrm{mmol} / \mathrm{g})$ & Surface area $\left(\mathrm{m}^{2} / \mathrm{g}\right)$ \\
\hline Laponite & $\mathbf{4}$ & 0.25 & 225 \\
& $\mathbf{5}$ & 0.10 & 218 \\
$\mathrm{SAC}-13$ & $\mathbf{4}$ & 0.08 & 84 \\
& $\mathbf{5}$ & 0.07 & 88 \\
$\mathrm{SiO}_{2}-\mathrm{CF}_{2} \mathrm{SO}_{3} \mathrm{H}$ & $\mathbf{4}$ & 0.37 & 377 \\
& $\mathbf{5}$ & 0.27 & 395 \\
\hline
\end{tabular}

Several authors have described that the reaction results are strongly dependent on the reaction conditions, ${ }^{4,6,12}$ in particular the relative amounts of styrene, nitrene precursor, $\mathrm{Cu}$ salt 
and chiral ligand. Therefore we tried to optimize the results in homogeneous phase before applying the immobilized catalysts. This preliminar study was carried out with the less expensive ligand 4, and the results obtained are gathered in Table 2.

Table 2. Results obtained from the homogeneous aziridination reactions promoted by bis(oxazoline)- $\mathrm{Cu}(\mathrm{OTf})_{2}$ in acetonitrile

\begin{tabular}{llllllll}
\hline $\begin{array}{l}\text { Styrene } \\
(\mathrm{mmol})\end{array}$ & $\begin{array}{l}\text { Nitrene } \\
\text { precursor } \\
(\mathrm{mmol})\end{array}$ & $\begin{array}{l}\mathrm{Cu}(\mathrm{OTf})_{2} \\
(\mathrm{mmol})\end{array}$ & $\begin{array}{l}\text { Chiral ligand } \\
(\mathrm{mmol})\end{array}$ & $\mathrm{T}\left({ }^{\circ} \mathrm{C}\right)$ & $\mathrm{t}(\mathrm{h})$ & ${\text { Yield }(\%)^{\mathrm{a}}}^{\text {\% ee }}$ & \\
\hline 1 & 1.5 & 0.15 & $\mathbf{4}(0.07)$ & 25 & 1 & $48^{\mathrm{c}}$ & $10^{\mathrm{c}}$ \\
1 & 1.5 & 0.15 & $\mathbf{4}(0.07)$ & 25 & 15 & $42^{\mathrm{c}}$ & $6^{\mathrm{c}}$ \\
1 & 1.5 & 0.05 & $\mathbf{4}(0.06)$ & -30 & 48 & 58 & 18 \\
5 & 1 & 0.05 & $\mathbf{4}(0.06)$ & 25 & 24 & 76 & 24 \\
5 & 1 & 0.05 & $\mathbf{5 ( 0 . 0 6 )}$ & 25 & 24 & 39 & 55 \\
\hline
\end{tabular}

${ }^{a}$ Isolated yield. ${ }^{b}$ Determined by HPLC, $\mathbf{3 R}$ is the major enantiomer. ${ }^{\mathrm{c}}$ Under identical conditions higher yields and enantioselectivities have been described. ${ }^{13}$

The optimal conditions were $5 \% \mathrm{Cu}$ catalyst (ligand $/ \mathrm{Cu}=1.2$ ) and styrene $/ \mathbf{2}=5$. Although enantioselectivity was not high, $24 \%$ ee with $(R)$-2-phenyl-1-(p-toluensulfonyl)aziridine (3R) as the major enantiomer, it can be improved up to $55 \%$ ee by using ligand 5 with the same direction in enantioselection, in agreement with previous results described in the literature. ${ }^{4}$ In view of these results, heterogeneous reactions were carried out under the same conditions and the results are gathered in Table 3.

As can be seen, the aziridination is efficiently promoted by the catalysts immobilized by ionpairing with anionic supports. Yields are not far from those obtained in homogeneous phase under similar conditions, even using amounts of catalyst as low as $0.6 \%$. A first advantage of heterogeneous over homogeneous catalysts is that it is possible to reuse them with nearly the same isolated yields. When bis(oxazoline) $\mathbf{4}$ is used in heterogeneous phase, the enantioselectivity of aziridination is not dependent on the type of support. In all the cases values around $25 \%$ ee are obtained, both with the freshly prepared and the reused catalysts, very similar to those obtained in solution with the same chiral ligand. As the major enantiomer is again $\mathbf{3 R}$, we can conclude that the support does not play any role in the stereochemical course of the reaction. Although laponite had shown important effects on the related cyclopropanation reaction with the same type of catalyst, ${ }^{15}$ in this case the use of a solvent with rather high dielectric constant such as acetonitrile precludes any complex-surface close interaction. 
Table 3. Results obtained from the heterogeneous aziridination reactions in acetonitrile at room temperature

\begin{tabular}{|c|c|c|c|c|c|c|}
\hline Ligand & Support & $\% \mathrm{Cu}$ & Run & $\mathrm{t}(\mathrm{h})$ & Yield $(\%)^{\mathrm{a}}$ & $\% \mathrm{ee}^{\mathrm{b}}$ \\
\hline- & Laponite & 5 & 1 & 5 & 62 & - \\
\hline - & $\mathrm{SiO}_{2}-\mathrm{CF}_{2} \mathrm{SO}_{3} \mathrm{H}$ & 5 & 1 & 4 & 69 & - \\
\hline \multirow[t]{6}{*}{4} & Laponite & 1.3 & 1 & 24 & 75 & 25 \\
\hline & & & 2 & 24 & 65 & 24 \\
\hline & SAC-13 & 0.6 & 1 & 24 & 73 & 21 \\
\hline & & & 2 & 24 & 64 & 20 \\
\hline & $\mathrm{SiO}_{2}-\mathrm{CF}_{2} \mathrm{SO}_{3} \mathrm{H}$ & 5 & 1 & 24 & 58 & 26 \\
\hline & & & 2 & 24 & 60 & 23 \\
\hline \multirow[t]{3}{*}{5} & Laponite & 7.4 & 1 & 24 & 60 & 2 \\
\hline & Laponite & 7.4 & 1 & 24 & $50^{\mathrm{c}}$ & $18^{\mathrm{c}}$ \\
\hline & $\mathrm{SiO}_{2}-\mathrm{CF}_{2} \mathrm{SO}_{3} \mathrm{H}$ & 5 & 1 & 24 & 57 & 0 \\
\hline
\end{tabular}

${ }^{\mathrm{a}}$ Isolated yield. ${ }^{\mathrm{b}}$ Determined by HPLC, $\mathbf{3 R}$ is the major enantiomer. ${ }^{\mathrm{c}}$ Using styrene as solvent.

Given that the enantioselectivity in solution is higher with ligand 5, the immobilized 5-Cu(II) complex was also tested in the aziridination reaction. Unfortunately no enantioselectivity was obtained with laponite or $\mathrm{SiO}_{2}-\mathrm{CF}_{2} \mathrm{SO}_{3} \mathrm{H}$ supports. The behavior of the immobilized complexes follows the same trend as in the case of cyclopropanation reactions, that is the same enantioselectivity both in homogeneous and heterogeneous phase with 4-Cu but a drastic reduction of enantioselectivity upon immobilization of 5-Cu. As the mechanisms of asymmetric aziridination ${ }^{16}$ and cyclopropanation ${ }^{17}$ seem to be different, this behavior must be related with the nature of the chiral bis(oxazoline) ligand. The bis(oxazoline) content of the solids can be estimated from the nitrogen analysis. In the case of 4-Cu complex supported on $\mathrm{SiO}_{2}-\mathrm{CF}_{2} \mathrm{SO}_{3} \mathrm{H}$ $\mathrm{N} / \mathrm{Cu}$ ratio has the expected value of 2 , accounting for the similarity between homogeneous and heterogeneous results. On the contrary, in the case of ligand 5 the $\mathrm{N} / \mathrm{Cu}$ ratio is only 0.7 , indicating that an important part of the copper centers are free of chiral ligand. The higher activity of this type of center, as shown by the result with $\mathrm{SiO}_{2}-\mathrm{CF}_{2} \mathrm{SO}_{3} \mathrm{Cu}$ (entry 2 in Table 3), accounts for the lack of enantioselectivity. The justification is more complicated in the case of laponite, given that the nitrogen analysis fits well with the exchange of the whole 5-Cu complex. In that case the use of acetonitrile, a solvent with high coordinating ability, may favor the substitution of the bis(oxazoline) with solvent molecules in the copper environment, creating in this way non-chiral active sites. In order to confirm this hypothesis the reaction was carried out with laponite-supported 5-Cu in styrene as solvent. In this case a modest $18 \%$ ee was obtained, in agreement with the result reported with an analogous zeolitic catalyst. ${ }^{14}$ The use of styrene as a solvent increases the enantioselectivity but reduces the yield, in spite of using a large excess of one reagent. This fact, which is due to the low solubility of the nitrene precursor, together with the only partial restoring of the selectivity, precludes the use of other solvents with low dielectric 
constant. It can be concluded that the immobilization of 5-Cu complex by electrostatic interactions cannot be properly performed due to its low binding constant, leading to the presence of free copper on the solid which noticeably reduces the enantioselectivity obtained with the supported catalyst.

\section{Experimental Section}

General Procedures. 2,2'-Isopropylidenebis[(4S)-4-phenyl-2-oxazoline](4) and 2,2'-isopropylidenebis[(4S)-4-tert-butyl-2-oxazoline] (5) were purchased from Aldrich. Laponite was obtained from Laporte Adsorbents. SAC-13 and $\mathrm{SiO}_{2}-\mathrm{CF}_{2} \mathrm{SO}_{3} \mathrm{H}$ were obtained from DuPont. ( $p$-Toluensulfonylimino)phenyliodinane (2) was obtained from $p$-toluensulfonamide and diacetoxyiodobenzene. ${ }^{18}$

\section{Preparation and characterization of the catalysts}

Preparation of the sodium form of the nafion-like supports. Prior to exchange with the chiral catalyst, $\mathrm{SAC}-13$ and $\mathrm{SiO}_{2}-\mathrm{CF}_{2} \mathrm{SO}_{3} \mathrm{H}$ were transformed into their sodium forms by passing $2 \mathrm{M}$ aqueous $\mathrm{NaCl}$ through a column of the solids until neutral $\mathrm{pH}$ was obtained. The solids were then washed with deionised water and dried under vacuum at $150{ }^{\circ} \mathrm{C}$ overnight.

Preparation of immobilized copper catalysts. To a solution of the bis(oxazoline) (1 mmol) in methanol $(20 \mathrm{~mL})$, was added $1 \mathrm{mmol}$ of $\mathrm{Cu}(\mathrm{OTf})_{2}$. Laponite $(1 \mathrm{~g})$ was slowly added to the above blue solution and the suspension was stirred at room temperature for $24 \mathrm{~h}$. The solid was filtered off, thoroughly washed with methanol and then with dichloromethane, and dried under air before use. The same procedure was used with the sodium form of nafion-like supports.

Characterization of the catalysts. Copper analyses were carried out by plasma emission spectroscopy on a Perkin-Elmer Plasma 40 emission spectrometer. Nitrogen analyses were carried out on a Perkin-Elmer 2400 elemental analyzer. Transmission FTIR spectra of selfsupported wafers evacuated $\left(<10^{-4}\right.$ Torr) at $50^{\circ} \mathrm{C}$ were recorded with a Mattson Genesis Series FTIR spectrophotometer. Surface areas were determined by $\mathrm{N}_{2}$ adsorption (BET) using a Micromeritics ASAP 2000 apparatus.

\section{Aziridination reactions}

2,2'-Isopropylidenebis[(4S)-4-phenyl-2-oxazoline] (4). (16.7 $\mathrm{mg}, 0.05 \mathrm{mmol})$ and $\mathrm{Cu}(\mathrm{OTf})_{2}$ $(21.7 \mathrm{mg}, 0.06 \mathrm{mmol})$ were dissolved in anhydrous dichloromethane $(4 \mathrm{~mL})$ at room temperature. This solution was passed through a microfilter and the solvent was evaporated under reduced pressure. The residue was dissolved in anhydrous acetonitrile $(3 \mathrm{~mL})$ and it was added under Ar atmosphere to a suspension of ( $p$-toluensulfonylimino)phenyliodinane (2) (373 mg, $1 \mathrm{mmol})$ in a solution of styrene $(520 \mathrm{mg}, 5 \mathrm{mmol})$ in anhydrous acetonitrile $(10 \mathrm{~mL})$. The reaction mixture was stirred at room temperature for $24 \mathrm{~h}$ and ethyl acetate $(25 \mathrm{~mL})$ was added. The resulting solution was filtered through a celite pad, which was washed with ethyl acetate 
$(50 \mathrm{~mL})$. The solvent of the combined organic solutions was evaporated under reduced pressure and the residue was purified by column chromatography on silica gel (dichloromethane/hexanes $=6: 4$ ) and the weight of pure aziridine was used to calculate the isolated yield.

A racemic mixture for spectroscopic characterization and chromatographic analysis was obtained from a reaction without chiral ligand under the same conditions. ${ }^{1} \mathrm{H}-\mathrm{NMR}(300 \mathrm{MHz}, \delta$ ppm, J Hz): 7.5-7.0 (m, 9H), 3.75 (dd, 1H, J=7.5, J=4.5), 2.96 (d, 1H, J=7.5), 2.40 (s, 3H), 2.36 $(\mathrm{d}, 1 \mathrm{H}, \mathrm{J}=4.5) .{ }^{13} \mathrm{C}-\mathrm{NMR}(75 \mathrm{MHz}, \delta \mathrm{ppm}): 144.6,135.0,131.1,129.7,128.5,128.3,127.9$, 126.5, 41.0, 35.9, 21.6. Elemental analysis: exp. C 65.89\%, H 5.51\%, N 5.08\%, S 11.70\%; calcd. for $\mathrm{C}_{15} \mathrm{H}_{15} \mathrm{NO}_{2} \mathrm{~S}$ : C $65.93 \%, \mathrm{H} \mathrm{5.49 \% ,} \mathrm{N} \mathrm{5.13 \% ,} \mathrm{S} \mathrm{11.72 \% .} \mathrm{Enantioselectivity} \mathrm{was} \mathrm{determined}$ by HPLC (Waters Alliance 2690, Photodiode Array Detector 2996) with a Chiralcel OJ column $(0.46 \mathrm{~cm} \rho \times 25 \mathrm{~cm})$ using hexane/isopropanol $(1: 1,0.8 \mathrm{~mL} / \mathrm{min})$ as eluent; retention times: $(R)-2$ phenyl-1-( $p$-toluensulfonyl)aziridine (3R) $13.7 \mathrm{~min}$, (S)-2-phenyl-1-( $p$-toluensulfonyl)aziridine (3S) $16.8 \mathrm{~min}$. Enantioselectivity was calculated by direct comparison of the peak areas integrated at $220 \mathrm{~nm}$. The peaks were assigned to the corresponding enantiomers by comparison with previously described results. ${ }^{4}$

The rest of the homogeneous reactions were carried out in the same way by changing the relative amounts of reagents and catalyst (see Table 2). In the case of heterogeneous reactions, the dried $\left(50^{\circ} \mathrm{C}\right.$ under vacuum overnight) solid catalyst was directly added to the suspension of ( $p$-toluensulfonylimino)phenyliodinane in the solution of styrene in anhydrous acetonitrile. After $24 \mathrm{~h}$, the catalyst was filtered, washed with acetonitrile $(10 \mathrm{~mL})$ and dried to be reused in the same way. The solution was treated (ethyl acetate, celite filtration and column chromatography) as in the case of homogeneous reactions.

\section{Acknowledgements}

This work was made possible by the generous financial support of the C.I.C.Y.T. (Project PPQ2002-04012).

\section{References}

1. Tanner, D. Angew. Chem. Int. Ed. 1994, 33, 599.

2. Andersson, P. G.; Harder, A.; Tanner, D.; Norby, P. O. Chem. Eur. J. 1995, 1, 12. Andersson, P. G.; Guijarro, D.; Tanner, D. Synlett 1996, 727.

3. (a) Jacobsen, E. N. In Comprehensive Asymmetric Catalysis; Jacobsen, E. N.; Pfaltz, A.; Yamamoto, H. Eds.; Springer: Berlin, 1999; pp 609-616. (b) Osborn, H. M.; Sweeney, J. Tetrahedron: Asymmetry 1997, 8, 1693. 
4. (a) Evans, D. A.; Faul, M. M.; Bilodeau, M. T.; Anderson, B. A.; Barnes, D. M. J. Am. Chem. Soc. 1993, 115, 5328. (b) Evans, D. A.; Faul, M. M.; Bilodeau, M. T. J. Am. Chem. Soc. 1994, 116, 2742.

5. Harm, A. M.; Knight, J. G.; Stemp, G. Synlett 1996, 677.

6. Södergren, M. J., Alonso, D. A.; Andersson, P. G. Tetrahedron: Asymmetry 1997, 8, 3563.

7. (a) Fraile, J. M.; García, J. I.; Mayoral, J. A.; Tarnai, T.; Harmer, M. A. J. Catal. 1999, 186, 214. (b) Fraile, J. M.; García, J. I.; Herrerías, C. I.; Mayoral, J. A.; Harmer, M. A. J. Catal. in press.

8. (a) Fraile, J. M.; García, J. I.; Mayoral, J. A.; Tarnai, T. Tetrahedron: Asymmetry 1998, 9, 3997. (b) Alonso, P. J.; Fraile, J. M.; García, J.; García, J. I.; Martínez, J. I.; Mayoral, J. A.; Sánchez, M. C. Langmuir 2000, 16, 5607.

9. Fraile, J. M.; García, J. I.; Harmer, M. A.; Herrerías, C. I.; Mayoral, J. A.; Reiser, O.; Werner, H. J. Mater. Chem. 2002, 12, 3290.

10. Harmer, M. A.; Farneth, W. E.; Sun, Q. J. Am. Chem. Soc. 1996, 118, 7708

11. Harmer, M. A.; Sun, Q.; Michalczyk, M. J.; Yang, Z. Chem. Commun. 1997, 1803.

12. Taylor, S.; Gullick, J.; McMorn, P.; Bethell, D.; Bulman-Page, P. C.; Hancock, F. E.; King, F.; Hutchings, G. J. J. Chem. Soc., Perkin Trans. 2 2001, 1714.

13. In reference 12 it has been described that the use of an excess (1.5 eq) of nitrene precursor and an amount of bis(oxazoline) below the stoichiometry increases the performance of the aziridination up to $91 \%$ yield and $73 \%$ ee after $1 \mathrm{~h}$ and $83 \%$ yield and $87 \%$ ee after $15 \mathrm{~h}$. On the contrary our results are in good agreement with the $29 \%$ ee reported for the reaction carried out with a five-fold excess of styrene promoted with a zeolitic $\mathrm{Cu}$-catalyst in reference 14 .

14. Langham, C.; Taylor, S.; Bethell, D.; McMorn, P.; Bulman-Page, P. C.; Willock, D. J.; Sly, C.; Hancock, F. E.; King, F.; Hutchings, G. J. J. Chem. Soc., Perkin Trans. 2 1999, 1043.

15. Fernández, A. I.; Fraile, J. M.; García, J. I.; Herrerías, C. I.; Mayoral, J. A.; Salvatella, L. Catal. Commun. 2001, 2, 165.

16. Müller, P.; Fruit, C. Chem. Rev. 2003, 103, 2905.

17. Fraile, J. M.; García, J. I.; Martínez-Merino, V.; Mayoral, J. A.; Salvatella, L. J. Am. Chem. Soc. 2001, 123, 7616.

18. Yamada, Y.; Yamamoto, T.; Okawara, M. Chem. Lett. 1975, 361. 